\title{
Assessment of Nutritional Status of Women in Rural Areas of Bengaluru District.
}

\author{
Maruthesha, A.M. ${ }^{1}$, Vijayalakshmi. D. ${ }^{2}$, Pritham, S.M. ${ }^{3}$, Vijay, S. Danaraddi ${ }^{4}$ \\ ${ }^{I}$ Assistant Professor, Department of Food Science, Agricultural and Horticultural Research Station, \\ Kathalagere. University of Agricultural and Horticultural Sciences, Shivamogga, Karnataka, India \\ ${ }^{2}$ Professors, Department of Food Science and Nutrition, College of Agriculture, \\ University of Agricultural Sciences, GKVK, Bangalore, Karnataka, India \\ ${ }^{3}$ Junior Research Fellow, Department of Food Science and Nutrition, Agricultural and Horticultural Research \\ Station, Kathalagere, University of Agricultural and Horticultural Sciences, Shivamogga, India. \\ ${ }^{4}$ Technical Assistant, AICRP-IFS, Agricultural and Horticultural Research Station, Kathalagere, University of \\ Agricultural and Horticultural Sciences, Shivamogga, India.
}

\begin{abstract}
The study was undertaken on nutritional status of rural women with the sample size of 200 respondents. Nutritional status reflects the health of a person and is influenced by the quality of foods eaten. Mean anthropometric measurement of rural women were $153.8 \mathrm{~cm}$ of height, $46.8 \mathrm{~kg}$ of weight. On comparison with the mean BMI standards, it was observed that 20 per cent of women were under nourished, 64 per cent of women were normal and 16 per cent women were obese. On comparison with the mean waist/hip ratio with standards, it was observed that 84 per cent were in normal category and 16 per cent were obese. Education, land holding, income and age had significant positive association with anthropometric measurements of rural women. The deficient level of hemoglobin existed in 53 per cent of rural women. The occurrence of morbidity symptoms was higher in rural women.
\end{abstract}

Key words: Anthropometry, Body Mass index, Hemoglobin, Nutrient deficiency, Rural women

\section{Introduction}

According to 2011 census the population of women in Karnataka was 38 million and out of these 28 million women belongs to rural area. Populations like rural agricultural labourers and tribal community are more vulnerable than the rest of the population in India. Nutritional status reflects the health of a person and is influenced by the quality of foods eaten and the ability of the body to utilize these foods. It is affected by various socio-economic factors including income, family size, occupation and educational status of the people. Musbe and Kumar, (2002) studied the prevalence of symptoms of malnutrition in a community is in turn a reflection of dietary consumption of its members. Majority of the population in developing and underdeveloped countries suffer from malnutrition and mostly the axe falls on the women and children. Keeping these facts in view, the study was conducted with objectives, to assess the anthropometric measurements of the rural women and to assess the hemoglobin, morbidity and nutrition deficiency symptoms of rural women.

\section{Material And Methods}

The nutritional status of subjects was assessed by nutritional anthropometry, diet survey and hemoglobin level. The anthropometric measurements viz., height in $\mathrm{cm}$, weight in $\mathrm{kg}$, waist and hip circumference of the respondents were recorded. The nutritional status was assessed by calculating BMI (Body Mass Index) and WH ratio (Waist to hip ratio). Height was measured accurately to the nearest $0.1 \mathrm{~cm}$ using vertical rod. The subject were made to remove the shoes and stand on the height rod platform by the scale with foot parallel with heals, shoulders and back of head in upright posture. Weights of the selected subjects were measured to the nearest point of $0.1 \mathrm{~kg}$ using a standard weighing balance (Jelliffe, 1966). The accuracy of the weight was ascertained by using standard weight. Height and weight of the subjects were used to calculate the body mass index. The subjects classified based on standard BMI (NIN, 1999). Waist circumference and hip circumference were used to calculate the waist to hip ratio. The abdominal obesity was judged by using the reference ratio given by (Lean et al., 1995). Clinical status was assessed by the investigator by visual method (presence of any deficiency symptoms at the time of survey). Modified ICMR proforma was used for the same. Morbidity status of the subjects was assessed by orally enquiring from the subjects whether they suffered from past six months any of the disorders mention in the Performa. Hemoglobin status is an indicator of iron status in an individual. The occurrence of iron as a component of the hemoglobin molecule has led to the use of hemoglobin determination to assess the adequacy of iron allowance. 


\section{Results And Discussion}

Table 1 depicts the mean anthropometric measurement of the SHG rural women. The mean height of SHG rural women was $153.8 \mathrm{cms}$, and the mean weight women $46.8 \mathrm{kgs}$. The average body mass index was 22.49 and the mean waist hip ratio 0.80 . According to body mass index women were categorized into normal, underweight and overweight (Fig.1 A). Sixty four per cent of respondents were normal followed by underweight $(20 \%)$ and 16 per cent respondents were overweight. Similar findings has been observed by Venkatalakshmi and Peramma, (2000) who reported that body mass index of agricultural farm women showed lower weight of normal grade (18.5-20.0). Also concluded that agriculture workers are main pillars of the country's economy and lower body weight decreases the productivity. Since the rural women belong to low socio-economic group in general, the reasons for prevalence of under nutrition could be due to the fact that women are over exhausted by the combination of reproductive demands and long term intake of lower amounts of food.

The waist/hip ratio of the rural women was also depicted in the (Fig 1.B). Among respondents 84 per cent of them were normal and 16 per cent of them were overweight. Estimates of waist/hip ratio provide a useful indication of nutritional status of underdeveloped countries, where population is often malnourished with little fat reserves, a change in this measurement reflects the total body stress. It is observed that measurement of waist/hip ratio has been used as a measure of total body subcutaneous fat. This observation was in concurrence with the findings of Menon et al. (2011) who reported that body weight was highest in older individuals, whereas no marked difference was observed in other variables like height. The possible factors of variation in waist/hip ratio, height and significant linear correlation with weight. Approximately 50 per cent of the women were under nourished due to low intake of food during early childhood and socio-economic status.

Correlation co-efficient of selected socio-economic factors on anthropometric measurements of women are depicted in Table 2. It is indicated that, except age with height and waist/hip ratio, family type with weight, height and BMI, remaining independent variables had positive relationship with anthropometric measurement. Education, land holding and income had a complete positive influence on anthropometric measurements and same results could be observed with respect to dietary intake also. From the present study it was observed that socio-economic factors viz. age and family income had a positive influence on anthropometric measurements. These observations are in line with the findings of Shwetha et al. (2011).

Table 3 shows the classification of rural women by hemoglobin range. The deficient level of hemoglobin existed in 53 per cent of women, low in 20 per cent and 27 per cent of women had acceptable level. This may be due to inadequacy of iron through dietary intake, which in turn affects the women as undernourished. Poor nutrition also affects her activity level and overall physical performance which reduce work capacity, increases fatigue and causes nutritional anemia. These findings are in line with the findings of Shobha et al. (2011) who reported that mean hemoglobin levels of women was $10.44 \mathrm{~g} / \mathrm{dl}$. Majority of women (59.21\%) were mild anemic, 23.3 per cent were moderately anemic and only 14.5 per cent were found to have normal hemoglobin level.

The occurrence of the illness among women is presented in Table 4. The illness reported among women in the study were pain in hands and legs, backache, headache, pain in abdomen, fever, weakness, cold and cough and acidity. This may be due to considerable amount of work load on women who spend 8 to 9 hours at work and after returning continue their day's work at home also. This was in conformity with findings of Jain and Singh (2013) who reported that more than three fourths of the farm women were frequently victimized for the health hazards namely skin irritation (88\%), headache (80\%), hardness of hand and feet (76\%), back/body ache $(74 \%)$ and whooping cough $(60 \%)$ as a result of their involvement in agricultural occupations.

The prevalence of various nutritional deficiencies among rural women of the study group is also presented in the same Table 5. The table reveals that the incidence of anemia, dental carries and gums-spongy bleeding was present in rural women. These results indicate that the rural women consumed inadequate iron and B-complex vitamins. Similar results were reported by Jain and Singh (2013) who reported that the women laborers suffered from B-complex deficiency followed by dental carries, bleeding gums and rough skin which may be due to type of work and climate.

\section{Conclusion}

Since the rural women belong to low socio-economic group in general, the reasons for prevalence of under nutrition could be due to the fact that women are over exhausted by the combination of reproductive demands and long term intake of lower amounts of food. Education, land holding, income and age had significant positive association with anthropometric measurements of rural women. The estimation of hemoglobin was carried out by finger prick method. The deficient level of hemoglobin existed in 53 per cent of rural women, low in 20 per cent and only 27 per cent had acceptable level. The occurrence of morbidity 
symptoms was higher in rural women. Such as pain in hands and legs, cold and acidity. Majority of the rural women were anemic, but some of the nutritional deficiency symptoms like dental carries and gums-spongy bleeding were observed.

\section{References}

[1]. JAIN, AND SINGH, 2013, A study on the nutritional status of women in the age group of 25-50 years working in sedentary job in jaipur city. The ind. J.Nutr. Diet. 40: 91-98.

[2]. JELLIFEE, D.B., 1966, Nutritional anthropometry. The assessment of the nutritional status of the community, WHO press, Geneva, p. $50-78$.

[3]. LEAN, M.E., HAN, T.S. AND MORRISON, C.E., 1995, Waist circumference as a measurement for indicating need for weight management. British medical Journal. 11: 638-642.

[4]. MENON, K., SHEAFF, S., THOMSON, C., GRAY, A., AND FERGUSON, L., ABHAY, S., KUMAR, D., TOTYA, G.S., AND PANDAV, C.S., 2011, Concurrent micronutrient deficiencies are prevalent in non-pregnant rural and tribal women from Central India. Nutrition. 2011, 27(4): 496-502.

[5]. MUSEBE, R.O. AND KUMAR, P., 2002, Dietary pattern and nutritional status of rural household in characters.Agril economics Reasearch Reviews, Vol., 15(2): 111-122.

[6]. NIN, 1999, Dietary guidelines for Indians- A manual, ICMR

[7]. RAO, V.K., 1995, Anthropometry for the assessment of various forms of malnutrition. Available approaches and their relative merits. Man in India. 75 (2): 195-207.

[8]. SHOBA, R., SMITA, J., PRADNYA, B., BHAIRAVI, P. AND ASNARI, K., 2011, Social dimensions related to anaemia among women of child bearing age from rural India. Public Health Nutrition. 14(2): 365-372.

[9]. SHWETHA, V., KUMAR, A.R., RAGHUVANSHI, R.S. AND SINGH, B.B., 2011, Nutritional status and knowledge of hill women on anemia: Effect of various socio-demographic factors. J. Human ecol., 33(1): 29-34.

[10]. VENKATALAKSHMI, P. AND PERAMMA, D., 2000, Basal metabolism rates of Chittor district agricultural workers. Indian. J. Nutri. Dietet. 40: 136-140.

[11]. WHO, 1992, The ICD-10 classification of mental and behavioral disorders: classification and diagnostic guidelines, World Health Organization, Geneva, PP : 240-281.

Table -1: Mean Anthropometric measurements of the rural women $(\mathbf{n}=\mathbf{2 0 0})$

\begin{tabular}{|c|c|c|}
\hline \multirow{2}{*}{ Attributes } & \multicolumn{2}{|c|}{ Women } \\
\cline { 2 - 3 } & Mean & SD \\
\hline Height $(\mathrm{cm})$ & 153.8 & 4.9 \\
\hline Weight $(\mathrm{kg})$ & 46.8 & 5.0 \\
\hline BMI & 22.49 & 10.19 \\
\hline Waist hip ratio & 0.80 & 0.268 \\
\hline
\end{tabular}

Table -2: Correlation co-efficient of Independent variables on Anthropometric measurements

\begin{tabular}{|l|c|c|c|c|c|c|}
\hline \multirow{2}{*}{ Independent variables } & \multicolumn{5}{|c|}{ Correlation co-efficient (r) } \\
\cline { 2 - 7 } & Weight $(\mathbf{k g})$ & Height $\mathbf{( c m})$ & BMI & Waist & Hip & Waist/hip ratio \\
\hline Age & $0.00569^{\mathrm{NS}}$ & $-0.21068^{*}$ & $0.00578^{\mathrm{NS}}$ & $0.04548^{\mathrm{NS}}$ & $0.01115^{\mathrm{NS}}$ & $-0.014^{\mathrm{NS}}$ \\
\hline Family type & $-0.031213^{\mathrm{NS}}$ & $-0.02684^{\mathrm{NS}}$ & $-0.1079^{\mathrm{NS}}$ & $0.2206^{*}$ & $0.21784^{*}$ & $0.0194^{\mathrm{NS}}$ \\
\hline Family size & 0.016824 & $-0.11652^{\mathrm{NS}}$ & $-0.0097^{\mathrm{NS}}$ & $0.30921^{* *}$ & $0.27853^{* *}$ & $0.04869^{\mathrm{NS}}$ \\
\hline Education & 0.0153642 & $0.23298^{*}$ & $0.13003^{\mathrm{NS}}$ & $0.1206^{\mathrm{NS}}$ & $0.1346^{\mathrm{NS}}$ & $0.11343^{\mathrm{NS}}$ \\
\hline Land holding & $0.1976^{*}$ & $0.17289^{\mathrm{NS}}$ & $0.18321^{\mathrm{NS}}$ & $0.19609^{*}$ & $0.20659^{*}$ & $0.11967^{\mathrm{NS}}$ \\
\hline Income & $0.426136^{*}$ & $0.39847^{* *}$ & $0.38279^{* *}$ & $0.3903^{* *}$ & $0.40509^{* *}$ & $0.35767^{* *}$ \\
\hline
\end{tabular}

* Significant at 5\%, ** Significant at 1\%, NS: Non significant

Table- 3: Classifications of women by hemoglobin range $\quad(\mathbf{n}=\mathbf{2 0 0})$

\begin{tabular}{|c|c|c|c|}
\hline Hemoglobin classification (WHO standard) & Respondents & Per cent & SD \\
\hline Deficient $(<10 \mathrm{~g} / \mathrm{dl})$ & 106 & 53 & 1.680 \\
\hline Low $(10-11.9 \mathrm{~g} / \mathrm{dl})$ & 40 & 20 & 1.560 \\
\hline Acceptable $(>12 \mathrm{~g} / \mathrm{dl})$ & 54 & 27 & 1.580 \\
\hline Total & $\mathbf{2 0 0}$ & $\mathbf{1 0 0}$ & \\
\hline
\end{tabular}

Table-4: Morbidity status of rural women

\begin{tabular}{|l|l|c|c|}
\hline \multirow{2}{*}{$\begin{array}{c}\text { S. } \\
\text { No. }\end{array}$} & \multicolumn{1}{|c|}{ Symptoms } & \multicolumn{2}{c|}{ Respondents (n=200) } \\
\cline { 3 - 4 } & & No. & Per cent \\
\hline 1. & Pain in hands and legs & 67 & 33.50 \\
\hline 2. & Giddiness and darkness in front of eyes & 48 & 24.00 \\
\hline 3. & Back ache & 40 & 20.00 \\
\hline 4. & Head ache & 120 & 60.00 \\
\hline 5. & Fatigue & 40 & 20.00 \\
\hline 6. & Body ache & 46 & 23.00 \\
\hline 7. & Fever & 48 & 24.00 \\
\hline 8. & Breathlessness & 12 & 6.00 \\
\hline 9. & Weakness & 19 & 9.50 \\
\hline 10. & Eye strain & 45 & 22.50 \\
\hline 11. & Cold & 67 & 33.50 \\
\hline 12. & Cough & 12 & 6.00 \\
\hline 13. & Acidity & 47 & 23.50 \\
\hline
\end{tabular}


\begin{tabular}{|l|l|}
\hline 14. & Tooth pain \\
\hline
\end{tabular}

@ Multiple response

6.00


Table-5: Nutrient deficiency signs prevalent in rural women

\begin{tabular}{|l|c|c|}
\hline \multirow{2}{*}{ Clinical symptoms } & \multicolumn{2}{c|}{ Respondents (n=200) } \\
\cline { 2 - 3 } & No. & Per cent \\
\hline Anaemia & 124 & 62.00 \\
\hline Dental caries & 31 & 15.50 \\
\hline Mottled enamel & 12 & 6.00 \\
\hline Gum spongy bleeding & 6 & 3.00 \\
\hline Normal & 17 & 8.50 \\
\hline
\end{tabular}

@ Multiple response

(A)

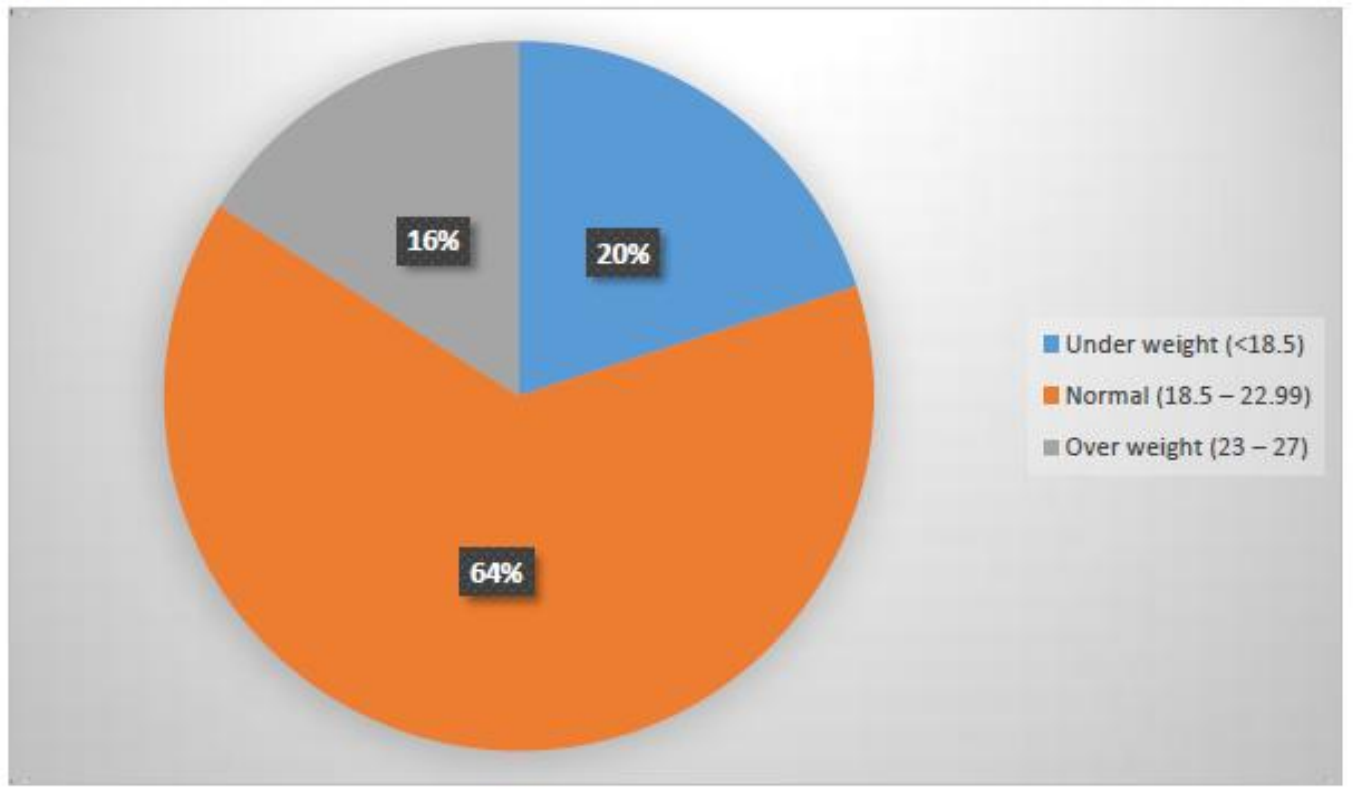

(B)

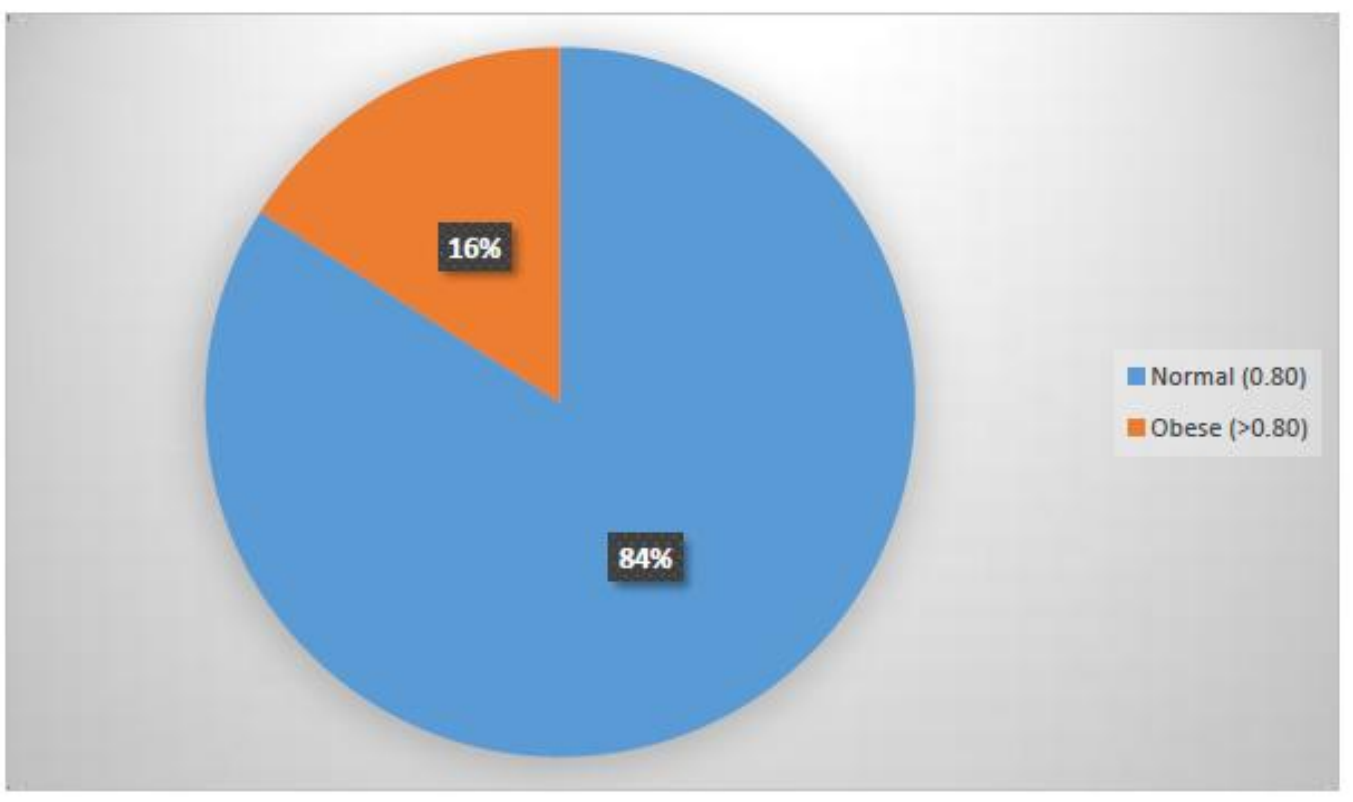

Fig 1 (A) Body Mass Index and (B)Waist to Hip ratio of rural women 